\title{
Cardiovascular Benefits of GLP-1-Based Therapies in Patients with Diabetes Mellitus Type 2: Effects on Endothelial and Vascular Dysfunction beyond Glycemic Control
}

\author{
Thomas Forst, ${ }^{1,2}$ Matthias M. Weber, ${ }^{2}$ and Andreas Pfüitzner ${ }^{1}$ \\ ${ }^{1}$ Institute for Clinical Research and Development, 55116 Mainz, Germany \\ ${ }^{2}$ First Medical Department, Johannes Gutenberg University, Mainz, Germany \\ Correspondence should be addressed to Thomas Forst, thomasf@ikfe.de
}

Received 4 January 2012; Accepted 6 February 2012

Academic Editor: Matteo Monami

Copyright (C) 2012 Thomas Forst et al. This is an open access article distributed under the Creative Commons Attribution License, which permits unrestricted use, distribution, and reproduction in any medium, provided the original work is properly cited.

Type 2 diabetes mellitus (T2DM) is a progressive multisystemic disease accompanied by vascular dysfunction and a tremendous increase in cardiovascular mortality. Numerous adipose-tissue-derived factors and beta cell dysfunction contribute to the increased cardiovascular risk in patients with T2DM. Nowadays, numerous pharmacological interventions are available to lower blood glucose levels in patients with type 2 diabetes. Beside more or less comparable glucose lowering efficacy, some of them have shown limited or probably even unfavorable effects on the cardiovascular system and overall mortality. Recently, incretin-based therapies (GLP-1 receptor agonists and DPP-IV inhibitors) have been introduced in the treatment of T2DM. Beside the effects of GLP-1 on insulin secretion, glucagon secretion, and gastrointestinal motility, recent studies suggested a couple of direct cardiovascular effects of GLP-1-based therapies. The goal of this paper is to provide an overview about the current knowledge of direct GLP-1 effects on endothelial and vascular function and potential consequences on the cardiovascular outcome in patients with T2DM treated with GLP-1 receptor agonists or DPP-IV inhibitors.

\section{Introduction}

The global prevalence of T2DM has been estimated at 171 million people and is projected to more than double by 2030 [1]. The epidemiological establishment of T2DM as a coronary artery disease equivalent has been confirmed in several investigations [2-4]. Type 2 diabetes mellitus (T2DM) is a progressive multisystemic disease accompanied by endothelial dysfunction [5-7] and an increased cardiovascular mortality $[3,8]$. Also several mechanistic pathways linking glucose metabolism with endothelial dysfunction are postulated; recent studies aimed to investigate the beneficial role of strict glycemic control using conventional treatment algorhythms failed to provide beneficial effects on cardiovascular mortality [9-11]. The accumulation and interaction of several metabolic and cardiovascular risk factors merge in the pathophysiology of diabetic vascular disease and the development of micro- and macrovascular complications. Diabetic vascular disease has been associated with an upregulation of reactive oxygen species and chronic inflammatory and hypercoagulable states, and as such with the pathogenesis of atherosclerosis and cardiovascular disease.

\section{Adipose Tissue, Insulin Resistance, and Beta Cell Function in Vascular Pathology}

Adipose tissue is assumed to play an integral role in the pathogenesis of vascular dysfunction and the development of T2DM [12]. As maturing pre-adipocytes differentiate to become adult adipocytes, they acquire the ability to synthesize hundreds of proteins. Adipose tissue releases a large number of cytokines and bioactive mediators with endocrine, autocrine, juxtacrine, and paracrine activity. These proinflammatory adipocytokines include TNF$\alpha$, IL-6, leptin, plasminogen activator inhibitor 1 (PAI1 ), angiotensinogen, resistin, and c-reactive protein, all of them well known to interfere with insulin sensitivity, blood 


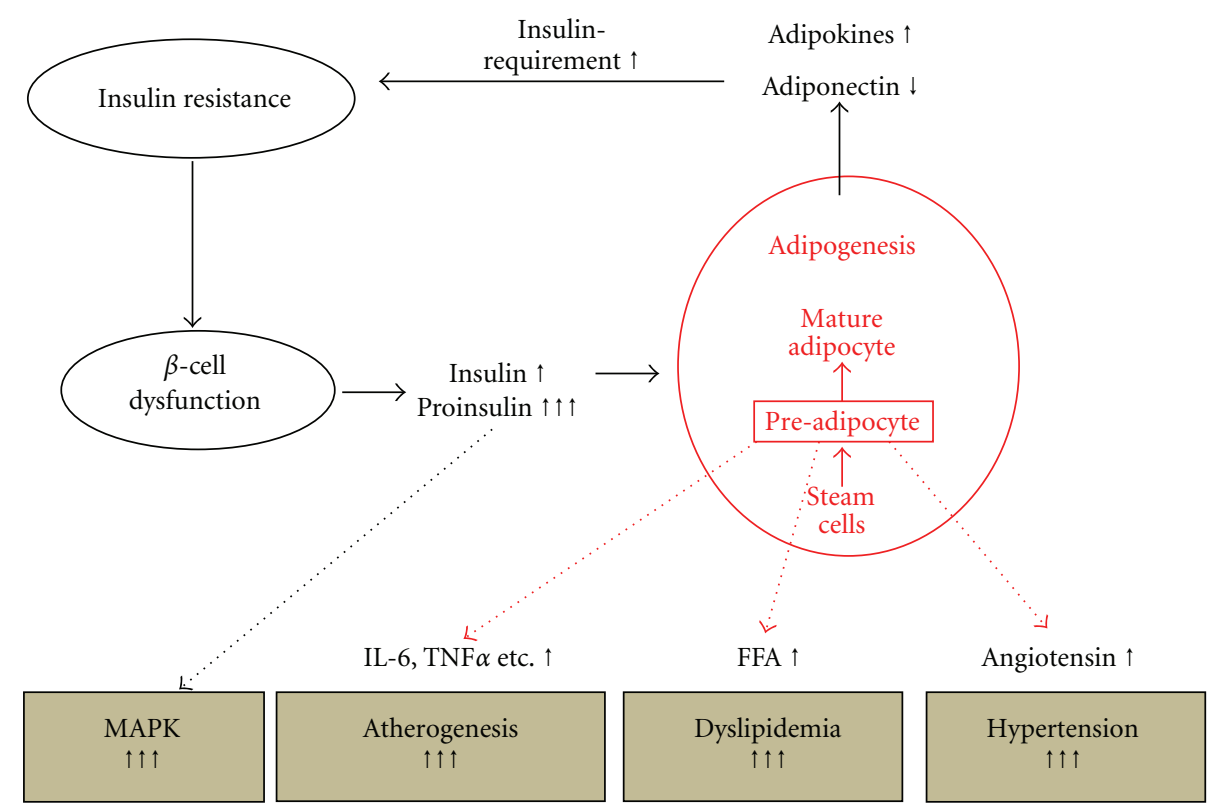

FIGURE 1: Schematic illustration of the central role of visceral adipose tissue in the generation of the atherogenic environment in obese patients. Visceral adipose tissue induces insulin resistance, thereby increasing insulin and proinsulin release from the beta cell. Unphysiological levels of insulin and proinsulin promote atherogenesis through the activation of endothelial MAPK. Preadipocytes secrete numerous adipocytokines involved in the pathogenesis of hypertension, dyslipidemia, and inflammation. (MAPK: mitogen-activated protein kinase, IL-6: interleukin-6, TNF $\alpha$ : tumor necrosis factor $\alpha$, FFA: free fatty acids).

pressure regulation, lipid metabolism, and inflammation (Figure 1). On the other hand, the release of adiponectin, an anti-inflammatory and vasoprotective adipokine, is reduced in insulin-resistant obese patients and in patients with T2DM [13]. In addition, it is likely that many more undiscovered fat cell-derived mediators are causally involved in cardiovascular health, insulin resistance, and the development of T2DM.

Epidemiological evidence suggests that cardiovascular risk begins to develop many years before the diagnosis of T2DM [14]. Increasing insulin resistance, associated with increasing visceral body fat, is associated with an increased risk for cardiovascular disease and is commonly comorbid with hypertension, dylipidemia, obesity, and a prothrombotic state [15-17]. As long as the pancreatic beta cells compensate for increasing insulin resistance with an augmented release of insulin, blood glucose will stay controlled, and the patient will not present, as per definition, with frank diabetes mellitus. There are strong prospective data that, even before deranging glucose levels, obesity and insulin resistance are associated with atherosclerosis and coronary heart disease $[18,19]$. However, it is the progressively deteriorating function of the beta cell, which ultimately leads to hyperglycemia and is critical for the manifestation of T2DM. There is increasing evidence that islet cell polymorphisms my account for the individual risk for beta cell breakdown and the manifestation of T2DM as defined by an increase in fasting and/or postprandial blood glucose levels $[20,21]$. The insulin/proinsulin ratio is used as a marker for the capability of the $\beta$ cell to convert intact proinsulin into insulin and C-peptide [21]. Preclinical and clinical studies of type 2 diabetes have identified proinsulin both as an indicator of decreasing beta cell function and a predictor of increased beta cell loss due to apoptosis and/or diminished neogenesis [21, 22]. Furthermore, a direct role of this prohormone in the development of cardiovascular disease has been suggested by numerous experimental and epidemiological studies. Increased intact proinsulin levels were found to be closely associated with the development of coronary heart disease involving subjects with and without diabetes [23-27]. In fact, the atherogenic potential of proinsulin was highlighted some years ago in a clinical trial, investigating the therapeutic potential of human proinsulin given as subcutaneous injections. In that study, an eightfold increase in cardiovascular events was observed during treatment with human proinsulin versus human regular insulin [28]. More recently, an association between increased plasma concentrations of proinsulin and the severity of angiographically characterized coronary heart disease has been reported [29]. Even the exact mechanism how proinsulin is involved in the pathogenesis of atherosclerosis is not completely recognized, it was already shown that PAI-1 activity increases after proinsulin administration in vitro [30]. Increased expression of PAI1 and vascular adhesion molecules have been associated with hyperglycemia-related endothelial cell dysfunction and a predisposition to accelerated atherogenesis [31]. There is increasing evidence that the atherogenic effects of proinsulin might, at least in part, be mediated by increasing PAI1 levels with subsequent inhibition of fibrinolysis and an augmented thrombogenic potency [32-34]. In accordance with this finding, the reduction of intact proinsulin levels during treatment with a PPAR $y$ agonist in T2DM was shown 
to be associated with a decrease in intima media thickness of the arteria carotis communis [35].

\section{Endothelial Dysfunction in Diabetes Mellitus}

Vascular wall dysfunction is a critical mediator of atherogenesis in patients with T2DM. The response to injury hypotheses of atherosclerosis supposed that the initial damage affects the arterial endothelium leading to endothelial dysfunction [36]. Endothelial dysfunction in patients with obesity and T2DM is characterized by an imbalance between endothelium-dependent vasodilatation and vasoconstriction as well as antithrombotic and prothrombotic factors. Nitric oxide (NO) maintains the vasodilatation and vasoprotective property of the endothelium and opposes the effects of vasoconstrictors such as endothelin 1 or angiotensin II [6, 37]. It inhibits leucocyte and platelet activation and helps to maintain the endothelium as smooth nonthrombotic barrier. Thus endothelial dysfunction is a prominent feature at various stages of atherogenesis, vessel occlusion, and tissue infarction [12]. In a study by Goldfine et al., endothelial function and NO bioavailability was evaluated in 38 individuals without a history of T2DM [38]. In this study, 19 patients were offspring of type 2 diabetes parents, while the other 19 had no first degree relatives with either T2DM or cardiovascular disease. Patients with a family history of diabetes were found to have significantly reduced endothelial function and nitric oxide (NO) bioavailability.

Beside the well-known metabolic effects of insulin, the hormone exerts important vascular effects through the activation of opposing intracellular signaling pathways. Under normal conditions, insulin provides vasodilatation and vasoprotective effects through the activation of the Phosphoinositol-3-Kinase pathway (PI-3 K) and promoting the release of NO. In contrast, in case of insulin resistance and an unphysiological release of insulin and proinsulin from the beta cells, the signal shifts from the vasoprotective PI$3 \mathrm{~K}$ pathway to the mitogen activated proteinkinase (MAPK) pathway (Figure 2). In this case, the vasodilating and beneficial effects of insulin turn over into the vasoconstrictive and mitogenic properties of insulin $[6,39]$.

\section{Effects of GLP-1 on Body Weight and Beta Cell Function}

Nowadays, numerous pharmacological interventions are available to lower blood glucose levels in patients with type 2 diabetes. Beside more or less comparable glucose lowering efficacy, some of them have shown limited or probably even unfavorable effects on the cardiovascular system and overall mortality [40-44]. Therefore, treatments in T2DM should be reevaluated not solely by judging their glucose lowering potency, but, moreover, on their overall effects on the cardiovascular risk profile and overall mortality in patients with T2DM.

Recently, incretin-based therapies have been introduced in the treatment of T2DM. Incretins, gut-derived hormones, predominantly glucagon peptide 1 (GLP-1), and gastric inhibitory polypeptide (GIP), are released in response to an ingested meal. They reduce blood glucose concentrations by enhancing the insulin release from pancreatic beta cells [45] and inhibiting postprandial glucagon secretion [46, 47] and gastric emptying after a meal [48]. However, only GLP-1 seemed to be suitable for the treatment of type 2 diabetic patients since the action of GIP was found to be grossly impaired in patients with T2DM [49]. Following its release from the L-cells into the blood stream, GLP-1 [736] is quickly cleaved by the enzyme dipeptidyl-peptidaseIV (DPP-IV) into the split product GLP-1 [9-39], which results in a half-life time of GLP-1 [7-39] of only 2 minutes. Therefore, strategies have been developed to increase the therapeutical window of GLP-1-based treatments by inhibiting the degrading enzyme DPP-IV or by providing exogenous agonists of GLP-1, which are resistant to the degradation by DPP-IV. At present, four DPP-IV inhibitors (Sitagliptin, Vildagliptin, Saxagliptin, and Linagliptin) and two GLP-1 receptor agonists (Exenatide and Liraglutide) are approved for the treatment of T2DM. In several studies, treatment with DPP-IV inhibitors and GLP-1 receptor agonists was shown to improve blood glucose control in type 2 diabetic patients without increasing the risk of hypoglycemia. While treatment with DPP-IV inhibitors was shown to be more or less weight neutral, treatment with the GLP-1 receptor agonists reduced body weight in the majority of patients with T2DM [50]. Beside these overall weight reducing effects of GLP-1 receptor agonists a pronounced reduction in visceral body fat was shown during treatment with Liraglutide [51]. In another study, treatment with the GLP-1 receptor agonist Exenatide resulted in a reduction in body weight, waist circumference, total body, and truncal fat mass by $6 \%, 5 \%, 11 \%$, and $13 \%$, respectively [52]. In addition, exenatide increased total adiponectin by $12 \%$ and reduced high-sensitive CRP by $61 \%$. Treatment with GLP1 receptor agonists has been consistently demonstrated to reduce blood pressure, as observed in clinical trials with exenatide or liraglutide [53-57]. Of interest is, that the reduction of blood pressure in most studies occurred even before weight reduction could be achieved, indicating direct effects of GLP-1 on blood pressure. The mechanisms beyond the blood pressure lowering effects of GLP-1 are still unclear. Beside changes in the release of adipokines from the adipose tissue, direct vasodilatory effects [58] and renal natriuretic effects [59] of GLP-1 might cause the beneficial effects of GLP-1 on blood pressure.

Recently, it has been reported that the vulnerability of the beta cell to release the prohormone intact proinsulin, instead of insulin and C-peptide, is linked to beta cell polymorphisms observed in three different risk alleles [22]. The mechanisms by which these risk alleles (HHEX, $\mathrm{CDKN} 2 \mathrm{~A} / \mathrm{B}$, and IGF2BP2) influence proinsulin processing are still a matter of debate. Loos et al. demonstrated that the genes of pro-protein convertases 1 and 2, which are key proteins in the conversion from proinsulin to insulin, exhibit binding sites for the $T$-cell transcription factor [60]. Therefore, an interaction with these pro-protein convertases may be a mechanism leading to increased proinsulin levels in carriers of the risk alleles [22]. As GLP-1 infusion 


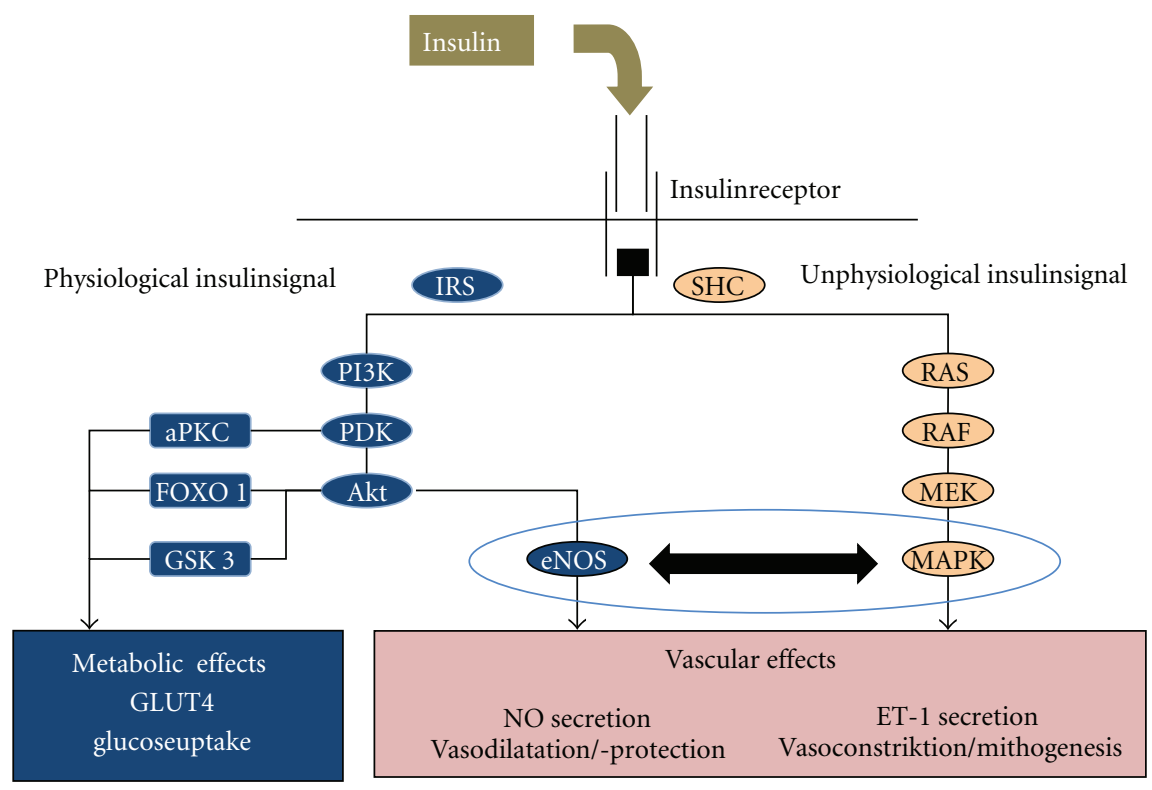

FIGURE 2: Schematic illustration of intracellular insulin signalling (aPKC: atypical Protein-Kinase C, eNOS: endothelial Nitric Oxide Synthase, ET1: Endothelin 1, FOX01: Forkhead Box01, IRS: Insulin Receptor Substrate, MAPK: Mitogen Activated Proteinkinase, MEK: Mitogen Activated Proteinkinase Kinase, NO: Nitric Oxide, PDK: Phosphoinositide-Dependent Kinase, PI3K: Phosphatidylinostol 3 Kinase, RAS, RAF: Proto-Oncogenes, SHC: Adapter Protein; adapted to [6]).

is able to normalize reduced proinsulin conversion, and GLP-1 signaling is impaired in carriers of the risk alleles in TCF7L2, it is conceivable that an attenuated GLP-1 signaling might lead to an impaired proinsulin processing [61]. Several clinical studies have shown an improvement in the Proinsulin/Insulin Ratio during treatment with GLP-1 receptor agonists $[62,63]$ and DPP-IV inhibitors [64-66]. In a cross-sectional study, postprandial intact proinsulin levels were significantly higher in sulfonylurea-treated patients compared to insulin and DPP-IV-inhibitor-treated patients and a non-diabetic control group [67]. As shown in Figure 3, the proinsulin/insulin ratio was comparable in between the DPP-IV-inhibitor-treated group and the nondiabetic control group, while it was evaluated in the sulfonylurea- and the insulin-treated group. In a recent study, the introduction of liraglutide treatment caused a pronounced decrease in intact proinsulin levels, which was found in parallel with a reduction in E-Selectin, asymmetric-dimethyl-arginine (ADMA), and PAI-1 levels, and an improvement in endothelial function [68]. Therefore, it seems conceivable that GLP1-based treatments do not only improve beta cell function by an induction of the proinsulin convertases but also reduce vascular risk by the reduction in circulating absolute proinsulin levels.

\section{Effects of GLP-1 on Endothelial and Cardiovascular Function}

GLP-1 acts through a distinct heptahelical G-proteincoupled receptor, which has been located not only in beta cells and the gastrointestinal tract, but also in the nervous system, heart, vascular smooth muscle cells, endothelial

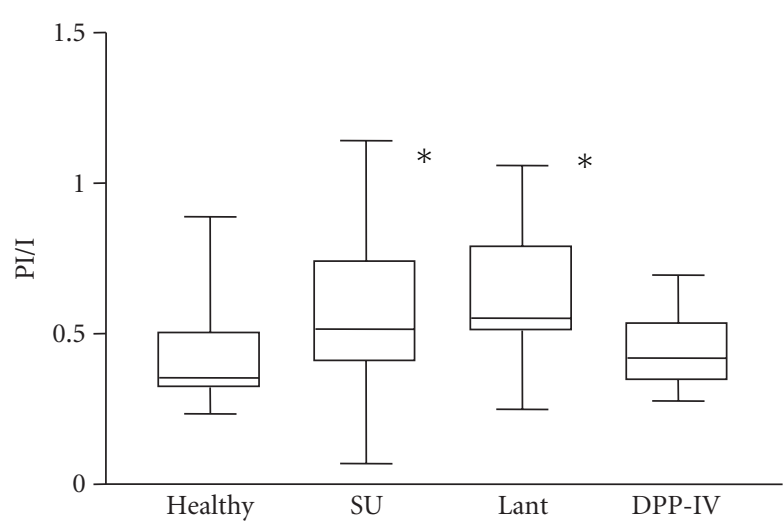

FIGURE 3: Postprandial proinsulin/insulin ratio in patients treated with sulfonylurea, insulin Glargine, or DPP-IV inhibitors compared to nondiabetic healthy controls $\left(^{*}: P<0.05\right.$ versus nondiabetic controls adapted to [67]).

cells, and macrophages $[45,58,70,71]$. GLP-1 appears to modulate a wide range of physiological effects, not only regulating blood glucose and metabolic control, but also directly affecting several cardiovascular pathways involved in atherogenesis. Binding of GLP-1 to the GLP-1 receptor in the myocardium leads to an increase in the production of cyclic adenosine monophosphate (cAMP) and an activation of protein kinase A (PKA), which results in an increase in glucose uptake and the inotropic effects in myocardial tissue. GLP-1 knockout mice exhibit reduced resting heart rate, elevated left ventricular and diastolic pressure, and increased left ventricular thickness compared with normal controls 


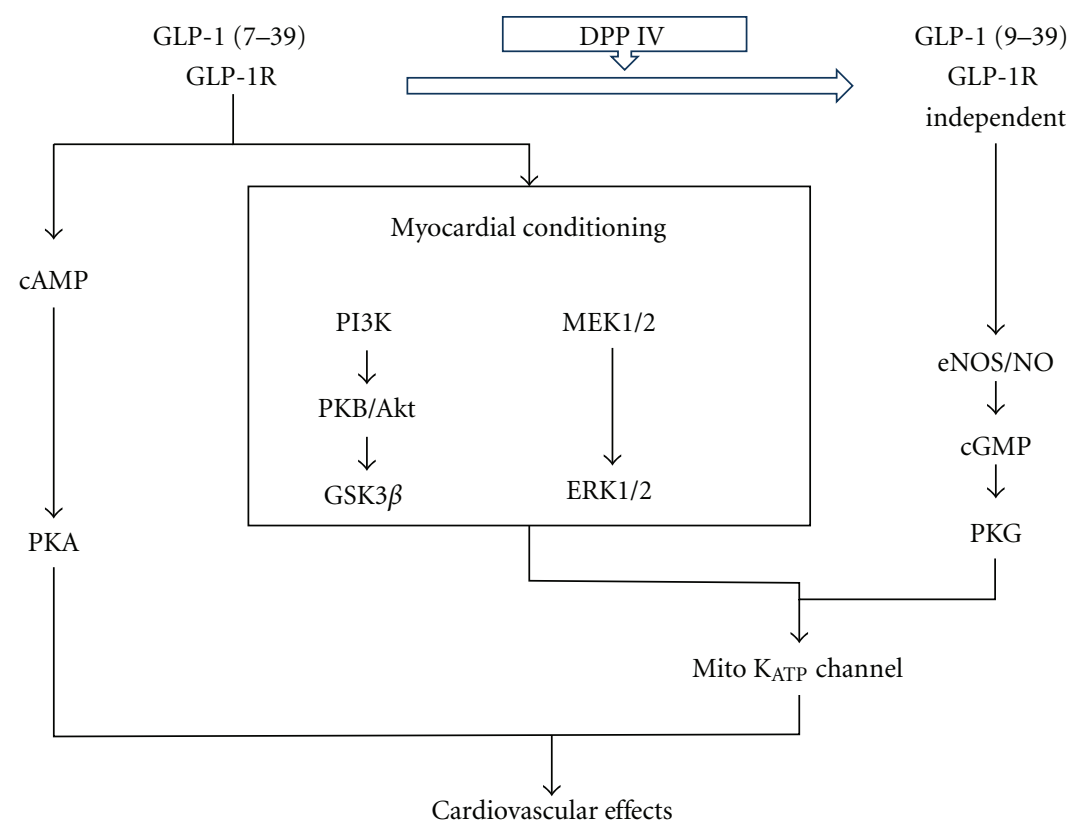

FIGURE 4: Schematic illustration of GLP-1-receptor-dependent and GLP-1-receptor-independent pathways in the signalling of GLP-1 associated cardiovascular effects (PI3K: phosphatidylinositol 3 kinase; cAMP: cyclic adenosine monophosphate, PKA: protein kinase A, PKB: protein kinase B, GSK3ß: glycogen synthase kinase 3 beta, MEK1/2: components of the MAP kinase cascade, ERK: extracellular-signalregulated kinase, NO: nitric oxide, eNOS: endothelial nitric oxide synthase, cGMP: cyclic guanosine monophosphate, PKG: protein kinase G; adapted to [69]).

[58]. In agreement with this findings, treatment with GLP1 or the GLP-1 receptor agonists was found to improve left ventricular function $[72,73]$ and to reduce circulating levels of brain natriuretic peptide (BNP) [74, 75]. GLP-1 increased functional cardiomyocyte viability in an isolated mouse heart reperfusion model but, unexpectedly, many of these actions were preserved in the GLP-1 knockout mouse model, suggesting cardiovascular effects that are independent of the GLP-1-receptor-mediated activation of cAMP/PKA [50]. Ban et al. studied the myocardial effects of GLP-1 (739) and GLP-1(9-39) under postischemic conditions in both wild-type and GLP1r (-/-) (GLP-1 receptor knockout mice) [58]. In wild-type mice, some of the effects of GLP-1 (739) could be reproduced by the truncated peptide GLP-1 (939). Those effects could also be induced by GLP1 (7-39) and GLP-1 (9-39) in the GLP1r (-/-) knockout mouse model. In addition, the beneficial effects of GLP-1 in the knockout mouse model could be abolished by the addition of the DPPIV inhibitor Sitagliptin and by the administration of the NOsynthase blocker L-NNA ( $\mathrm{N}^{G}$-nitro-arginine). This leads to the hypothesis of a two pathway mechanism for the protective cardiovascular action of GLP-1. One that depends on the GLP-1 receptor mediated action with inotropic, glucose uptake stimulating, ischemic preconditioning effects, and one, receptor independent vasodilatatory pathway, which is mediated by NO (Figure 4).

Growing lines of evidence demonstrate beneficial effects of GLP-1 on endothelium and vascular smooth muscle cells [58, 76-78]. In human vascular endothelial cells, liraglutide caused eNOS phosphorylation and potentiated
eNOS activity with an increased nitric oxide production [79]. In endothelial cells, isolated from human coronary arteries, GLP-1 rapidly activates endothelial nitric oxide synthase (eNOS), promotes cell proliferation, and inhibits glucolipoapoptosis [80]. In healthy, nondiabetic, subjects, GLP1 infusion enhanced the acetylcholine-mediated increase in forearm blood flow, while no such effect could be observed on endothelial-independent vasodilatation after sodium nitroprusside [78]. Interestingly, in that study, the beneficial effects of GLP-1 on endothelial function were damped by the addition of glyburide, but not by glimepiride. In type 2 diabetic patient with coronary artery disease, infusion of GLP-1 increased flow-mediated vasodilatation in the brachial artery, affirming the NO-dependent mechanism of GLP-1 in the vascular system [81]. In this study, no such effect could be observed in nondiabetic healthy controls.

\section{Other Potential Cardiovascular Benefits}

Treatment with the GLP-1 receptor agonists, liraglutide and exenatide, was shown to reduce PAI-1 levels in patients with T2DM [68, 74, 75, 82]. In cultured human vascular endothelial cells, Liraglutide inhibited the expression of tumor necrosis factor- $\alpha$ (TNF $\alpha$ ) and the hyperglycemiamediated induction of VCAM-1 and PAI-1 [74, 80]. This may be of relevance as elevated PAI-1 levels have been implicated in endothelial cell dysfunction [83]. In a previous study, 14 weeks of treatment with liraglutide significantly decreased PAI-1 levels by 25\% [74]. Complementing the 
beneficial effect on PAI-1 levels, liraglutide attenuates the induction of PAI-1 and vascular adhesion molecules in vitro [31].

A recent metaanalysis of the 6 trials from the LEAD program revealed that treatment with the GLP-1 receptor agonist liraglutide decreased hsCRP levels by $23 \%$ from baseline till 6 months [84]. In a study comparing exenatide and glargine treatment, treatment with exenatide over a period of 12 months reduces hsCRP levels by $61 \%$ [52].

In addition to the effects on myocardium and the endothelial cells, GLP-1 may also have effects on atherogenesis through direct interactions with monocytes or macrophages. Treatment with Exenatide significantly inhibited monocyte adhesion in the aorta of C57BL/6 mice [85]. In apoE $(-/-)$ mice, the same treatment reduced monocyte adhesion to the endothelium and suppressed atherogenesis.

As pointed out by Zilversmit many years ago, atherosclerosis could be considered to be a prandial phenomenon [86]. Therefore, GLP-1 might serve as a metabolic and vasoprotective factor evolving its main effects after the ingestion of a meal. In a study by Koska et al. postprandial endothelial function was investigated in IGT subjects and in patients with recently diagnosed T2DM by reactive hyperemia peripheral arterial tonometry [87]. In that study, a single dose of Exenatide resulted in a significant improvement in postprandial endothelial function compared with placebo administration. In another study, intravenous GLP (7-39) infusion resulted in a significant improvement of postprandial FMD during an OGT and during a hyperglycemic clamp procedure [88]. The improvement in FMD was paralleled by a reduced postprandial increase in nitrotyrosine and 8 iso-PGF2a levels. These results suggest that GLP-1 has the potential to reduce glucose load, oxidative stress and to improve endothelial function especially in the postprandial state.

How far all the previously observed pleiotropic effects of GLP-1 will translate in a reduction of micro- and/or macrovascular complications in patients with T2DM is still not established. In a retrospective analysis of the LifeLink database, patients treated with the GLP-1 receptor agonist Exenatide were less likely to have a CVD event (HR 0.81, $P=0.01)$ and lower rates of CVD-related hospitalization (HR $0.88, P=0.02$ ) [89]. A recent meta-analysis assessing the cardiovascular outcome of GLP-1-receptor agonists in clinical trials up to November 2010 revealed a significant lower rate of major cardiovascular events in GLP-1-receptoragonist-treated patients compared to placebo [90]. Ongoing randomized prospective clinical studies will provide more evidence about potential clinical long-term effects of GLPreceptor agonist or DPP-IV inhibitor treatment in patients with T2DM at cardiovascular risk.

\section{Funding}

T. Forst, M. M. Weber, and A. Pfützner received research funds, speaker and advisory fees from Novo Nordisk, E. Lilly, Novartis, and Boehringer Ingelheim.

\section{References}

[1] S. Wild, G. Roglic, A. Green, R. Sicree, and H. King, "Global prevalence of diabetes: estimates for the year 2000 and projections for 2030," Diabetes Care, vol. 27, no. 5, pp. 10471053, 2004.

[2] A. Juutilainen, S. Lehto, T. Rönnemaa, K. Pyörälä, and M. Laakso, "Type 2 diabetes as a "coronary heart disease equivalent": an 18-year prospective population-based study in Finnish subjects," Diabetes Care, vol. 28, no. 12, pp. 29012907, 2005.

[3] S. M. Haffner, S. Lehto, T. Rönnemaa, K. Pyörälä, and M. Laakso, "Mortality from coronary heart disease in subjects with type 2 diabetes and in nondiabetic subjects with and without prior myocardial infarction," The New England Journal of Medicine, vol. 339, no. 4, pp. 229-234, 1998.

[4] L. Whiteley, S. Padmanabhan, D. Hole, and C. Isles, "Should diabetes be considered a coronary heart disease risk equivalent? Results from 25 years of follow-up in the Renfrew and Paisley survey," Diabetes Care, vol. 28, no. 7, pp. 1588-1593, 2005.

[5] J. Calles-Escandon and M. Cipolla, "Diabetes and endothelial dysfunction: a clinical perspective," Endocrine Reviews, vol. 22, no. 1, pp. 36-52, 2001.

[6] T. Forst, C. Hohberg, and A. Pfützner, "Cardiovascular effects of disturbed insulin activity in metabolic syndrome and in type 2 diabetic patients," Hormone and Metabolic Research, vol. 41, no. 2, pp. 123-131, 2009.

[7] E. Cosson, I. Pham, P. Valensi, J. Pariès, J. R. Attali, and A. Nitenberg, "Impaired coronary endothelium-dependent vasodilation is associated with microalbuminuria in patients with type 2 diabetes and angiographically normal coronary arteries," Diabetes Care, vol. 29, no. 1, pp. 107-112, 2006.

[8] T. K. Schramm, G. H. Gislason, L. Køber et al., "Diabetes patients requiring glucose-lowering therapy and nondiabetics with a prior myocardial infarction carry the same cardiovascular risk: a population study of 3.3 million people," Circulation, vol. 117, no. 15, pp. 1945-1954, 2008.

[9] W. T. Friedewald, J. B. Buse, J. T. Bigger et al., "Effects of intensive glucose lowering in type 2 diabetes," The New England Journal of Medicine, vol. 358, no. 24, pp. 2545-2559, 2008.

[10] A. Patel, S. MacMahon, J. Chalmers et al., "Intensive blood glucose control and vascular outcomes in patients with type 2 diabetes," The New England Journal of Medicine, vol. 358, no. 24, pp. 2560-2572, 2008.

[11] W. Duckworth, C. Abraira, T. Moritz et al., "Glucose control and vascular complications in veterans with type 2 diabetes," The New England Journal of Medicine, vol. 360, no. 2, pp. 129139, 2009.

[12] D. C. W. Lau, B. Dhillon, H. Yan, P. E. Szmitko, and S. Verma, "Adipokines: molecular links between obesity and atheroslcerosis," American Journal of Physiology, vol. 288, no. 5, pp. H2031-H2041, 2005.

[13] N. Klöting, M. Fasshauer, A. Dietrich et al., "Insulin-sensitive obesity," American Journal of Physiology, vol. 299, no. 3, pp. E506-E515, 2010.

[14] F. B. Hu, M. J. Stampfer, S. M. Haffner, C. G. Solomon, W. C. Willett, and J. E. Manson, "Elevated risk of cardiovascular disease prior to clinical diagnosis of type 2 diabetes," Diabetes Care, vol. 25, no. 7, pp. 1129-1134, 2002.

[15] N. Ishizaka, Y. Ishizaka, E. Takahashi et al., "Association between insulin resistance and carotid arteriosclerosis in subjects with normal fasting glucose and normal glucose 
tolerance," Arteriosclerosis, Thrombosis, and Vascular Biology, vol. 23, no. 2, pp. 295-301, 2003.

[16] G. M. Reaven, "Insulin resistance, the insulin resistance syndrome, and cardiovascular disease," Panminerva Medica, vol. 47, no. 4, pp. 201-210, 2005.

[17] K. J. Ausk, E. J. Boyko, and G. N. Ioannou, "Insulin resistance predicts mortality in nondiabetic individuals in the U.S," Diabetes Care, vol. 33, no. 6, pp. 1179-1185, 2010.

[18] H. C. McGill Jr., C. A. McMahan, E. E. Herderick et al., "Obesity accelerates the progression of coronary atherosclerosis in young men," Circulation, vol. 105, no. 23, pp. 2712-2718, 2002.

[19] E. Cho, J. E. Manson, M. J. Stampfer et al., "A prospective study of obesity and risk of coronary heart disease among diabetic women," Diabetes Care, vol. 25, no. 7, pp. 1142-1148, 2002.

[20] S. Cauchi, S. D. Guerra, H. Choquet et al., "Meta-analysis and functional effects of the SLC30A8 rs13266634 polymorphism on isolated human pancreatic islets," Molecular Genetics and Metabolism, vol. 100, no. 1, pp. 77-82, 2010.

[21] A. Fritsche, A. Madaus, N. Stefan et al., "Relationships among age, proinsulin conversion, and $\beta$-cell function in nondiabetic humans," Diabetes, vol. 51, supplement 1, pp. S234-S239, 2002.

[22] K. Kirchhoff, F. Machicao, A. Haupt et al., "Polymorphisms in the TCF7L2, CDKAL1 and SLC30A8 genes are associated with impaired proinsulin conversion," Diabetologia, vol. 51, no. 4, pp. 597-601, 2008.

[23] M. Alssema, J. M. Dekker, G. Nijpels, C. D. A. Stehouwer, L. M. Bouter, and R. J. Heine, "Proinsulin concentration is an independent predictor of all-cause and cardiovascular mortality: an 11-year follow-up of the Hoorn study," Diabetes Care, vol. 28, no. 4, pp. 860-865, 2005.

[24] J. Y. Oh, E. Barrett-Connor, and N. M. Wedick, "Sex differences in the association between proinsulin and intact insulin with coronary heart disease in nondiabetic older adults: the Rancho Bernardo study," Circulation, vol. 105, no. 11, pp. 1311-1316, 2002.

[25] M. Wohlin, J. Sundström, J. Ärnlöv, B. Andrén, B. Zethelius, and L. Lind, "Impaired insulin sensitivity is an independent predictor of common carotid intima-media thickness in a population sample of elderly men," Atherosclerosis, vol. 170, no. 1, pp. 181-185, 2003.

[26] B. Zethelius, H. Lithell, C. N. Hales, and C. Berne, "Insulin sensitivity, proinsulin and insulin as predictors of coronary heart disease. A population-based 10-year, follow-up study in 70-year old men using the euglycaemic insulin clamp," Diabetologia, vol. 48, no. 5, pp. 862-867, 2005.

[27] B. Zethelius, L. Byberg, C. N. Hales, H. Lithell, and C. Berne, "Proinsulin is an independent predictor of coronary heart disease: report from a 27-year follow-up study," Circulation, vol. 105, no. 18, pp. 2153-2158, 2002.

[28] J. A. Galloway, S. A. Hooper, C. T. Spradlin et al., "Biosynthetic human proinsulin: review of chemistry, in vitro and in vivo receptor binding, animal and human pharmacology studies, and clinical trial experience," Diabetes Care, vol. 15, no. 5, pp. 666-692, 1992.

[29] E. Z. Jia, Z. J. Yang, T. B. Zhu et al., "Proinsulin is an independent predictor of the angiographical characteristics of coronary atherosclerosis," Cardiology, vol. 110, no. 2, pp. 106111,2008

[30] T. K. Nordt, D. J. Schneider, and B. E. Sobel, "Augmentation of the synthesis of plasminogen activator inhibitor type-1 by precursors of insulin: a potential risk factor for vascular disease," Circulation, vol. 89, no. 1, pp. 321-330, 1994.
[31] H. Liu, A. E. Dear, L. B. Knudsen, and R. W. Simpson, "A long-acting glucagon-like peptide-1 analogue attenuates induction of plasminogen activator inhibitor type-1 and vascular adhesion molecules," Journal of Endocrinology, vol. 201, no. 1, pp. 59-66, 2009.

[32] T. K. Nordt, C. Bode, and B. E. Sobel, "Stimulation in vivo of expression of intra-abdominal adipose tissue plasminogen activator inhibitor type I by proinsulin," Diabetologia, vol. 44, no. 9, pp. 1121-1124, 2001.

[33] A. Festa, R. D’Agostino Jr., L. Mykkänen et al., "Relative contribution of insulin and its precursors to fibrinogen and PAI-1 in a large population with different states of glucose tolerance: the Insulin Resistance Atherosclerosis Study (IRAS)," Arteriosclerosis, Thrombosis, and Vascular Biology, vol. 19, no. 3, pp. 562-568, 1999.

[34] C. J. Lyon and W. A. Hsueh, "Effect of plasminogen activator inhibitor-1 in diabetes mellitus and cardiovascular disease," American Journal of Medicine, vol. 115, no. 8, supplement 1, pp. 62S-68S, 2003.

[35] T. Forst, C. Hohberg, S. D. Fuellert et al., "Pharmacological $\operatorname{PPAR} \gamma$ stimulation in contrast to beta cell stimulation results in an improvement in adiponectin and proinsulin intact levels and reduces intima media thickness in patients with type 2 diabetes," Hormone and Metabolic Research, vol. 37, no. 8, pp. 521-527, 2005.

[36] R. Ross, "The pathogenesis of atherosclerosis: a perspective for the 1990s," Nature, vol. 362, no. 6423, pp. 801-809, 1993.

[37] S. Verma and T. J. Anderson, "Fundamentals of endothelial function for the clinical cardiologist," Circulation, vol. 105, no. 5, pp. 546-549, 2002.

[38] A. B. Goldfine, J. A. Beckman, R. A. Betensky et al., "Family history of diabetes is a major determinant of endothelial function," Journal of the American College of Cardiology, vol. 47, no. 12, pp. 2456-2461, 2006.

[39] K. Mather, T. J. Anderson, and S. Verma, "Insulin action in the vasculature: physiology and pathophysiology," Journal of Vascular Research, vol. 38, no. 5, pp. 415-422, 2001.

[40] D. J. Margolis, O. Hoffstad, and B. L. Strom, "Association between serious ischemic cardiac outcomes and medications used to treat diabetes," Pharmacoepidemiology and Drug Safety, vol. 17, no. 8, pp. 753-759, 2008.

[41] D. T. Eurich, F. A. McAlister, D. F. Blackburn et al., "Benefits and harms of antidiabetic agents in patients with diabetes and heart failure: systematic review," British Medical Journal, vol. 335, no. 7618, pp. 497-501, 2007.

[42] A. D. Rao, N. Kuhadiya, K. Reynolds, and V. A. Fonseca, "Is the combination of sulfonylureas and metformin associated with an increased risk of cardiovascular disease or all- cause mortality?" Diabetes Care, vol. 31, no. 8, pp. 1672-1678, 2008.

[43] S. Bolen, L. Feldman, J. Vassy et al., "Systematic review: comparative effectiveness and safety of oral medications for type 2 diabetes mellitus," Annals of Internal Medicine, vol. 147, no. 6, pp. 386-399, 2007.

[44] M. J. Davies, "Insulin secretagogues," Current Medical Research and Opinion, vol. 18, supplement 1, pp. s22-s30, 2002.

[45] T. J. Kieffer and J. F. Habener, "The glucagon-like peptides," Endocrine Reviews, vol. 20, no. 6, pp. 876-913, 1999.

[46] T. Matsuyama, R. Komatsu, M. Namba, N. Watanabe, H. Itoh, and S. Tarui, "Glucagon-like peptide-1 (7-36 amide): a potent glucagonostatic and insulinotropic hormone," Diabetes Research and Clinical Practice, vol. 5, no. 4, pp. 281-284, 1988.

[47] G. C. Weir, S. Mojsov, G. K. Hendrick, and J. F. Habener, "Glucagonlike peptide I (7-37) actions on endocrine pancreas," Diabetes, vol. 38, no. 3, pp. 338-342, 1989. 
[48] A. Wettergren, B. Schjoldager, P. E. Mortensen, J. Myhre, J. Christiansen, and J. J. Holst, "Truncated GLP-1 (proglucagon 78-107-amide) inhibits gastric and pancreatic functions in man," Digestive Diseases and Sciences, vol. 38, no. 4, pp. 665673,1993

[49] M. A. Nauck, M. M. Heimesaat, C. Orskov, J. J. Holst, R. Ebert, and W. Creutzfeldt, "Preserved incretin activity of glucagonlike peptide 1 [7-36 amide] but not of synthetic human gastric inhibitory polypeptide in patients with type- 2 diabetes mellitus," The Journal of Clinical Investigation, vol. 91, no. 1, pp. 301-307, 1993.

[50] M. H. Davidson, "Cardiovascular effects of glucagonlike peptide-1 agonists," American Journal of Cardiology, vol. 108, no. 3, supplement, pp. 33B-41B, 2011.

[51] J. Jendle, M. A. Nauck, D. R. Matthews et al., "Weight loss with liraglutide, a once-daily human glucagon-like peptide1 analogue for type 2 diabetes treatment as monotherapy or added to metformin, is primarily as a result of a reduction in fat tissue," Diabetes, Obesity and Metabolism, vol. 11, no. 12, pp. 1163-1172, 2009.

[52] M. C. Bunck, M. Diamant, B. Eliasson et al., "Exenatide affects circulating cardiovascular risk biomarkers independently of changes in body composition," Diabetes Care, vol. 33, no. 8, pp. 1734-1737, 2010.

[53] D. D. Mafong and R. R. Henry, "The role of incretins in cardiovascular control," Current Hypertension Reports, vol. 11, no. 1, pp. 18-22, 2009.

[54] D. C. Klonoff, J. B. Buse, L. L. Nielsen et al., "Exenatide effects on diabetes, obesity, cardiovascular risk factors and hepatic biomarkers in patients with type 2 diabetes treated for at least 3 years," Current Medical Research and Opinion, vol. 24, no. 1, pp. 275-286, 2008.

[55] M. Marre, J. Shaw, M. Brändle et al., "Liraglutide, a oncedaily human GLP-1 analogue, added to a sulphonylurea over 26 weeks produces greater improvements in glycaemic and weight control compared with adding rosiglitazone or placebo in subjects with Type 2 diabetes (LEAD-1 SU)," Diabetic Medicine, vol. 26, no. 3, pp. 268-278, 2009.

[56] J. B. Buse, J. Rosenstock, G. Sesti et al., "Liraglutide once a day versus exenatide twice a day for type 2 diabetes: a 26week randomised, parallel-group, multinational, open-label trial (LEAD-6)," The Lancet, vol. 374, no. 9683, pp. 39-47, 2009.

[57] T. Okerson, P. Yan, A. Stonehouse, and R. Brodows, "Effects of exenatide on systolic blood pressure in subjects with type 2 diabetes," American Journal of Hypertension, vol. 23, no. 3, pp. 334-339, 2010.

[58] K. Ban, M. H. Noyan-Ashraf, J. Hoefer, S. S. Bolz, D. J. Drucker, and M. Husain, "Cardioprotective and vasodilatory actions of glucagon-like peptide 1 receptor are mediated through both glucagon-like peptide 1 receptor-dependent and -independent pathways," Circulation, vol. 117, no. 18, pp. 2340-2350, 2008.

[59] J. P. Gutzwiller, S. Tschopp, A. Bock et al., "Glucagonlike peptide 1 induces natriuresis in healthy subjects and in insulin-resistant obese men," The The Journal of Clinical Endocrinology and Metabolism, vol. 89, no. 6, pp. 3055-3061, 2004.

[60] R. J. F. Loos, P. W. Franks, R. W. Francis et al., “TCF7L2 polymorphisms modulate proinsulin levels and $\beta$-cell function in a British europid population,” Diabetes, vol. 56, no. 7, pp. 1943 1947, 2007.

[61] M. Stumvoll, A. Fritsche, N. Stefan, E. Hardt, and H. Häring, "Evidence against a rate-limiting role of proinsulin processing for maximal insulin secretion in subjects with impaired glucose tolerance and $\beta$-cell dysfunction," The Journal of Clinical Endocrinology and Metabolism, vol. 86, no. 3, pp. 1235-1239, 2001.

[62] T. Vilsbøll, B. Brock, H. Perrild et al., "Liraglutide, a oncedaily human GLP-1 analogue, improves pancreatic B-cell function and arginine-stimulated insulin secretion during hyperglycaemia in patients with Type 2 diabetes mellitus," Diabetic Medicine, vol. 25, no. 2, pp. 152-156, 2008.

[63] R. A. DeFronzo, R. E. Ratner, J. Han, D. D. Kim, M. S. Fineman, and A. D. Baron, "Effects of exenatide (exendin-4) on glycemic control and weight over 30 weeks in metformintreated patients with type 2," Diabetes Care, vol. 28, no. 5, pp. 1092-1100, 2005.

[64] S. Del Prato, A. H. Barnett, H. Huisman, D. Neubacher, H.-J. Woerle, and K. A. Dugi, "Effect of linagliptin monotherapy on glycaemic control and markers of $\beta$-cell function in patients with inadequately controlled type 2 diabetes: a randomized controlled trial," Diabetes, Obesity and Metabolism, vol. 13, no. 3, pp. 258-267, 2011.

[65] R. E. Pratley, A. Schweizer, J. Rosenstock et al., "Robust improvements in fasting and prandial measures of $\beta$-cell function with vildagliptin in drug-naïve patients: analysis of pooled vildagliptin monotherapy database," Diabetes, Obesity and Metabolism, vol. 10, no. 10, pp. 931-938, 2008.

[66] I. Raz, M. Hanefeld, L. Xu, C. Caria, D. Williams-Herman, and H. Khatami, "Efficacy and safety of the dipeptidyl peptidase4 inhibitor sitagliptin as monotherapy in patients with type 2 diabetes mellitus," Diabetologia, vol. 49, no. 11, pp. 2564-2571, 2006.

[67] S. Pscherer, M. Larbig, B. von Stritsky et al., "In type 2 diabetic patients, insulin glargine is associated with lower postprandial release of intact compared with sulfonyurea treatment," Journal of Diabetes Science and Technology. In press.

[68] T. Forst, G. Michelson, F. Ratter et al., "Addition of liraglutide in patients with Type 2 diabetes well controlled on metformin monotherapy improves several markers of vascular function," Diabetic Medicine. In press.

[69] K. Ban, S. Hui, D. J. Drucker, and M. Husain, "Cardiovascular consequences of drugs used for the treatment of diabetes: potential promise of incretin-based therapies," Journal of the American Society of Hypertension, vol. 3, no. 4, pp. 245-259, 2009.

[70] S. M. Gardiner, J. E. March, P. A. Kemp, T. Bennett, and D. J. Baker, "Possible involvement of GLP-1(9-36) in the regional haemodynamic effects of GLP-1(7-36) in conscious rats," British Journal of Pharmacology, vol. 161, no. 1, pp. 92$102,2010$.

[71] E. Tomas and J. F. Habener, "Insulin-like actions of glucagon-like peptide-1: a dual receptor hypothesis," Trends in Endocrinology and Metabolism, vol. 21, no. 2, pp. 59-67, 2010.

[72] L. A. Nikolaidis, S. Mankad, G. G. Sokos et al., "Effects of glucagon-like peptide-1 in patients with acute myocardial infarction and left ventricular dysfunction after successful reperfusion," Circulation, vol. 109, no. 8, pp. 962-965, 2004.

[73] G. G. Sokos, L. A. Nikolaidis, S. Mankad, D. Elahi, and R. P. Shannon, "Glucagon-like peptide-1 infusion improves left ventricular ejection fraction and functional status in patients with chronic heart failure," Journal of Cardiac Failure, vol. 12, no. 9, pp. 694-699, 2006.

[74] J. P. Courrèges, T. Vilsbøll, M. Zdravkovic et al., "Beneficial effects of once-daily liraglutide, a human glucagonlike peptide-1 analogue, on cardiovascular risk biomarkers in 
patients with type 2 diabetes," Diabetic Medicine, vol. 25, no. 9, pp. 1129-1131, 2008.

[75] R. M. Bergenstal, C. Wysham, L. MacConell et al., "Efficacy and safety of exenatide once weekly versus sitagliptin or pioglitazone as an adjunct to metformin for treatment of type 2 diabetes (DURATION-2): a randomised trial," The Lancet, vol. 376, no. 9739, pp. 431-439, 2010.

[76] H. A. Golpon, A. Puechner, T. Welte, P. V. Wichert, and C. O. Feddersen, "Vasorelaxant effect of glucagon-like peptide(7-36)amide and amylin on the pulmonary circulation of the rat," Regulatory Peptides, vol. 102, no. 2-3, pp. 81-86, 2001.

[77] G. Richter, O. Feddersen, U. Wagner, P. Barth, R. Goke, and B. Goke, "GLP-1 stimulates secretion of macromolecules from airways and relaxes pulmonary artery," American Journal of Physiology, vol. 265, no. 4, pp. L374-L381, 1993.

[78] A. Basu, N. Charkoudian, W. Schrage, R. A. Rizza, R. Basu, and M. J. Joyner, "Beneficial effects of GLP-1 on endothelial function in humans: dampening by glyburide but not by glimepiride," American Journal of Physiology, vol. 293, no. 5, pp. E1289-E1295, 2007.

[79] Y. Hattori, T. Jojima, A. Tomizawa et al., "A glucagon-like peptide-1 (GLP-1) analogue, liraglutide, upregulates nitric oxide production and exerts anti-inflammatory action in endothelial cells," Diabetologia, vol. 53, no. 10, pp. 2256-2263, 2010.

[80] H. Liu, Y. Hu, R. W. Simpson, and A. E. Dear, "Glucagonlike peptide- 1 attenuates tumour necrosis factor- $\alpha$-mediated induction of plasmogen activator inhibitor-1 expression," Journal of Endocrinology, vol. 196, no. 1, pp. 57-65, 2008.

[81] T. Nyström, M. K. Gutniak, Q. Zhang et al., "Effects of glucagon-like peptide- 1 on endothelial function in type 2 diabetes patients with stable coronary artery disease," American Journal of Physiology, vol. 287, no. 6, pp. E1209-E1215, 2004.

[82] T. Vilsbøll, M. Zdravkovic, T. Le-Thi et al., "Liraglutide, a long-acting human glucagon-like peptide-1 analog, given as monotherapy significantly improves glycemic control and lowers body weight without risk of hypoglycemia in patients with type 2 diabetes," Diabetes Care, vol. 30, no. 6, pp. 1608 1610, 2007.

[83] S. M. Nicholl, E. Roztocil, and M. G. Davies, "Plasminogen activator system and vascular disease," Current Vascular Pharmacology, vol. 4, no. 2, pp. 101-116, 2006.

[84] J. Plutzky, A. J. Garber, A. Falahati et al., "The once daily human GLP-1-analogue, liraglutide significantly reduces markers of cardiovascular risk in type 2 diabetes: a metaanalysis of six clinical trials," European Heart Journal, vol. 30, pp. 917-919, 2009.

[85] M. Arakawa, T. Mita, K. Azuma et al., "Inhibition of monocyte adhesion to endothelial cells and attenuation of atherosclerotic lesion by a glucagon-like peptide-1 receptor agonist, exendin4," Diabetes, vol. 59, no. 4, pp. 1030-1037, 2010.

[86] D. B. Zilversmit, "Atherogenesis: a postprandial phenomenon," Circulation, vol. 60, no. 3, pp. 473-485, 1979.

[87] J. Koska, E. A. Schwartz, M. P. Mullin, D. C. Schwenke, and P. D. Reaven, "Improvement of postprandial endothelial function after a single dose of exenatide in individuals with impaired glucose tolerance and recent-onset type 2 diabetes," Diabetes Care, vol. 33, no. 5, pp. 1028-1030, 2010.

[88] A. Ceriello, K. Esposito, R. Testa, A. R. Bonfigli, M. Marra, and D. Giugliano, "The possible protective role of glucagonlike peptide1 on endothelium during the meal and evidence for an "endothelial resistance" to glucagon-like peptide 1 in diabetes," Diabetes Care, vol. 34, no. 3, pp. 697-702, 2011.
[89] J. H. Best, B. J. Hoogwerf, W. H. Herman et al., "Risk of cardiovascular disease events in patients with type 2 diabetes prescribed the Glucagon-Like Peptide 1 (GLP-1) receptor agonist exenatide twice daily or other glucose-lowering therapies: a retrospective analysis of the lifelink database," Diabetes Care, vol. 34, no. 1, pp. 90-95, 2011.

[90] M. Monami, F. Cremasco, C. Lamanna et al., "Glucagon-like peptide-1 receptor agonists and cardiovascular events: a metaanalysis of randomized clinical trials," Experimental Diabetes Research, vol. 2011, Article ID 215764, 10 pages, 2011. 


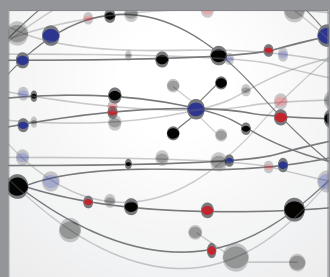

The Scientific World Journal
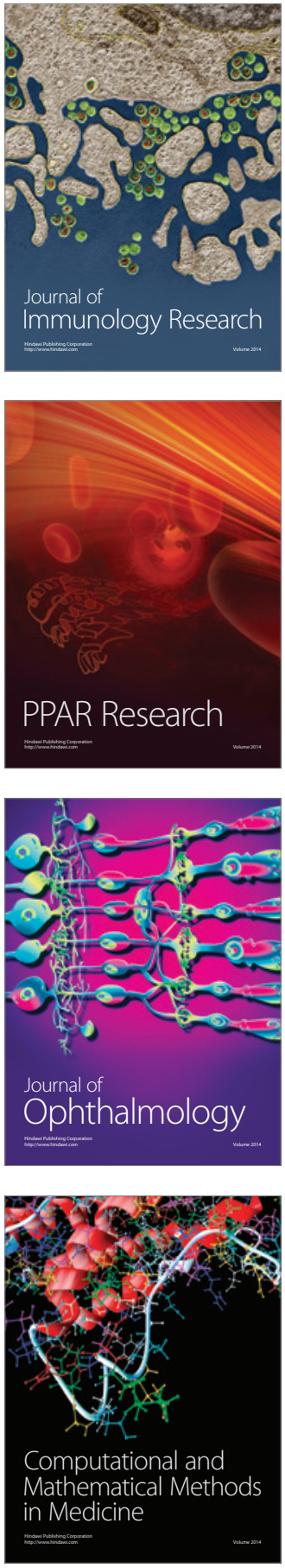

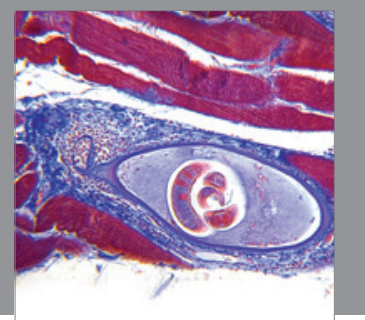

Gastroenterology

Research and Practice
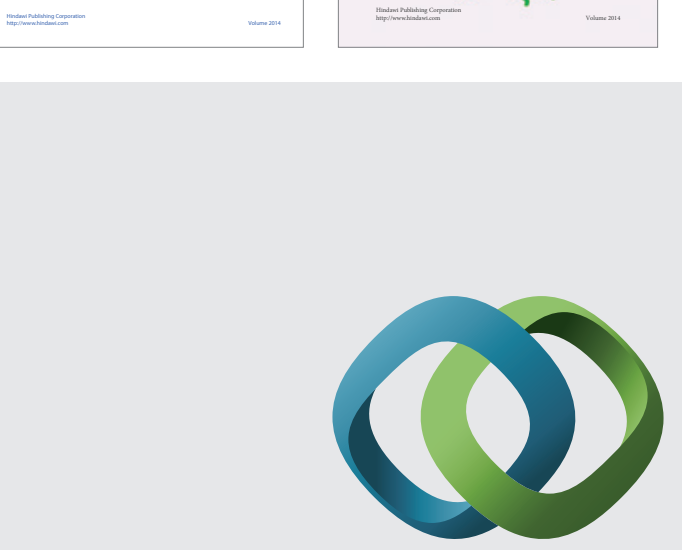

\section{Hindawi}

Submit your manuscripts at

http://www.hindawi.com
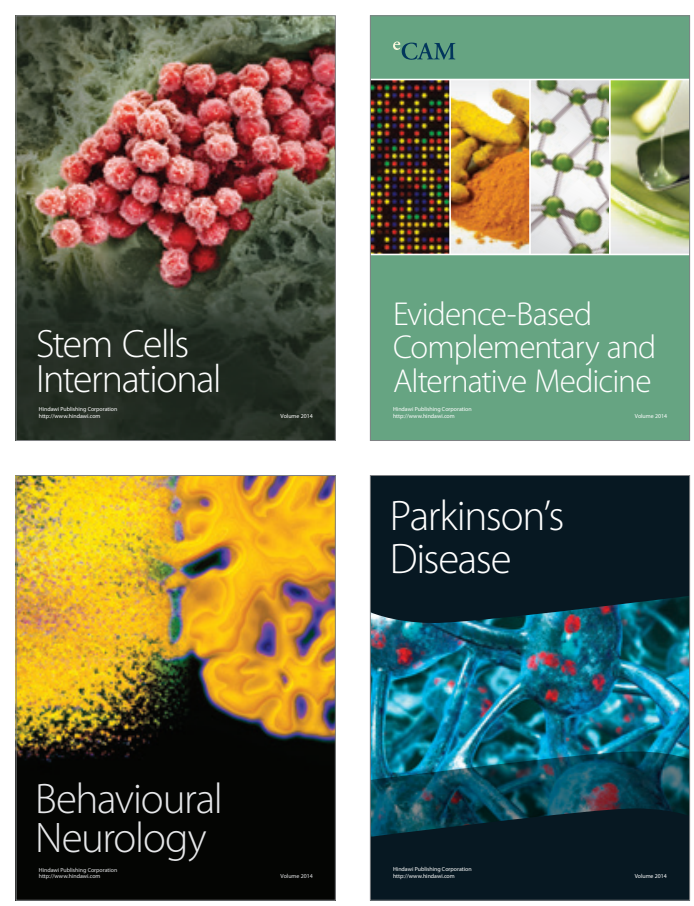

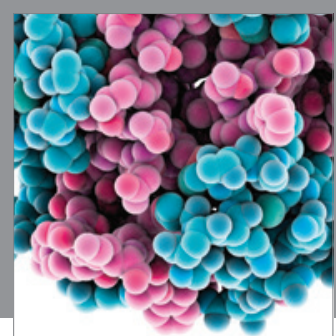

Journal of
Diabetes Research

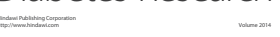

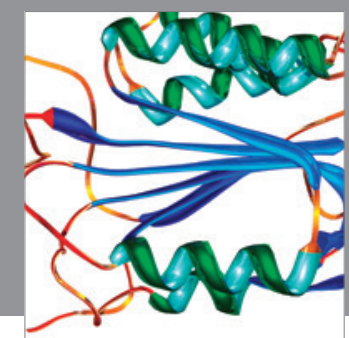

Disease Markers
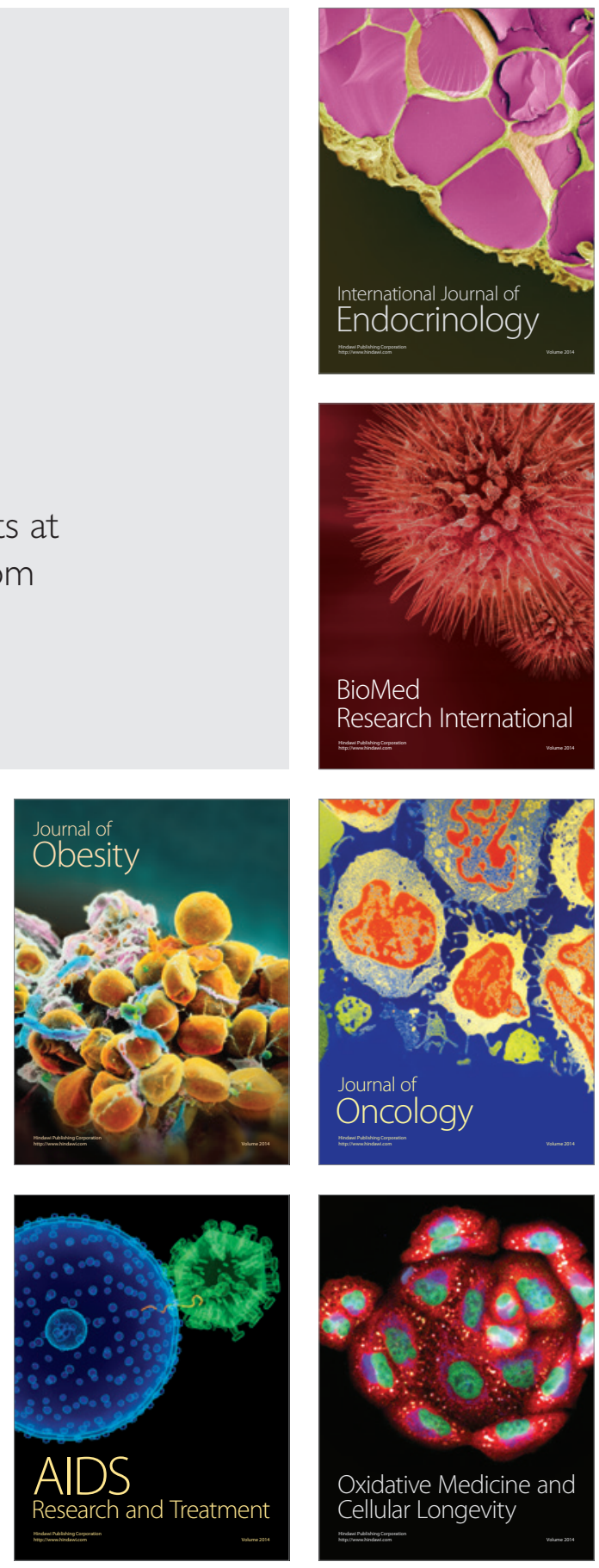